\title{
Educational Efficacy of Diverse Strategies on Knowledge and Skill of Nursing Students Regarding Neonatal Resuscitation
}

\author{
MISHAL LIAQAT 1 , MUHAMMAD HUSSAIN², MUHAMMAD AFZAL ${ }^{3}$ \\ ${ }^{1} M S$ Nursing, Lahore School of Nursing, The University of Lahore, Pakistan \\ ${ }^{2}$ Associate Professor, Lahore School of Nursing, The University of Lahore, Pakistan \\ ${ }^{3}$ Principal, Lahore School of Nursing, The University of Lahore, Pakistan \\ Correspondence to Ms. Mishal Liaqat, E-mail: mishee861@gmail.com, Cell: 0344-1481666,
}

\begin{abstract}
Background: The educational efficacy in resuscitation could be improved by enhancing instructional design through different innovative approaches especially in resource-limited settings.

Aim: To determine the educational efficacy of diverse strategies on knowledge and skill of nursing students regarding neonatal resuscitation.

Study design: Quasi-experimental study.

Place and duration of study: School of Nursing, Allama lqbal Medical College, Lahore from $1^{\text {st }}$ November 2020 to $30^{\text {th }}$ April 2021.

Methodology: Sixty-five nursing students of $1^{\text {st }}$ and $2^{\text {nd }}$ professionals were selected. The education on neonatal resuscitation consists of diverse educational strategies including didactic lecture, video, simulation, and selfpractice sessions in the simulation laboratory of a public school of nursing in Lahore, Pakistan. The data on knowledge and skill was assessed two times before and after the intervention.

Results: The study showed a significant $(p<0.001)$ change in knowledge and skill after education. Nearly, all students had poor knowledge and skill before education. The knowledge had been improved as $40.0 \%$ of students achieved good, and 53.3\% achieved fair knowledge level.

Conclusion: The diverse educational strategies in neonatal resuscitation significantly improve nursing students' knowledge and skill.

Keywords: Neonatal resuscitation, Education, Nursing students, Knowledge, Skill
\end{abstract}

\section{INTRODUCTION}

Neonatal resuscitation is the most common neonatal emergency at the time of birth. 1 Nearly, 1 in 10 newborns requires some form of resuscitation and $<1 \%$ required more advanced measures including chest compressions and medications. ${ }^{2}$ Effective resuscitation at birth is associated with reducing neonatal morbidity and mortality. ${ }^{3}$ Therefore, skilled health professionals must be present on-site to handle these emergencies. ${ }^{4}$ That is not possible without frequent training and education in the field of resuscitation.

Since many studies reported the improvement of cognitive and technical skills in neonatal resuscitation among health care providers after educational training. ${ }^{5-7}$ However, the educational efficacy is inclined by the instructional design including but not limited to skill learning, deliberate practice, mentoring, feedback, evaluation, and other advanced educational approaches ${ }^{8}$ that are crucial to optimize learning outcomes. ${ }^{9}$ Consequently, enhancing instructional design in different innovative approaches can improve educational outcomes.

Nursing is an evolving profession searching continuously for evidence-based strategies to advance clinical practice and patient outcomes. The role of effective supervision, mentorship, and new strategies for improving knowledge and skill are crucial for improving nursing practice. ${ }^{10}$ Nursing students expose to neonatal resuscitation during their clinical rotation. Yet, often less prepared to handle paediatric emergencies such as neonatal resuscitation ${ }^{11}$. The knowledge regarding neonatal resuscitation was assessed by Malarvizhi et $\mathrm{al}^{12}$

Received on 03-05-2021

Accepted on 20-07-2021 among 85 nursing students in Coimbatore and found that $52 \%$ of them had insufficient knowledge and $48 \%$ had nearly adequate knowledge while no student had enough information on neonatal resuscitation. Thus, expressing a dire need of developing effective educational strategies in the field of resuscitation especially in the preservice areas. Hence, the current study determines the educational efficacy of diverse strategies on knowledge and skill of nursing students regarding neonatal resuscitation.

\section{MATERIALS AND METHODS}

The study was a quasi-experimental (one group preposttest) conducted between December 2020 to May 2021. Sixty-five nursing students of $1^{\text {st }}$ and $2^{\text {nd }}$ professionals were selected. The setting was the simulation lab at a public school of nursing in Lahore, Pakistan. Written informed consent was taken from all the students. The nursing students enrolled in the first and second year of Bachelor of Science in Nursing were selected through convenient sampling. The nursing students who gave informed consent had ages between 18-24 years and did not receive any previous training and education in neonatal resuscitation were included in the study. A 12 weeks educational intervention consists of theoretical lectures on neonatal resuscitation, video, Scenario-based simulation session, and self-learning practice session were given by trained instructors. The students were divided into groups for practice sessions and each group contained 5-6 students. Data on knowledge and skill were collected two times before and after the educational intervention through validating tools.

The demographic form contains information regarding year of study, language, residential area, marital status, and status on previous neonatal resuscitation exposure. Data on knowledge was collected through a knowledge 
questionnaire. ${ }^{13,14}$ The total score of each student's knowledge was graded ${ }^{15}$ as $0-49 \%$ poor, $50-74 \%$ fair, and $75-100 \%$ score with a good level of knowledge. The skill was assessed through a checklist by Rovamo et al. ${ }^{16}$ The total score of each student skill was graded ${ }^{15}$ as $0-49 \%$ unsatisfactory, $50-74 \%$ satisfactory, and $75-100 \%$ score with good skill. The two assessors evaluate students' skills before and after intervention in the simulation lab.

The data analysis was performed by using the SPSS24. Chi-square was used for categorical data. While, paired sample t-test was used to compare the difference in knowledge and skill in pre-and post-educational intervention. A $p$-value $\leq$ of 0.05 was taken as significant.

\section{RESULTS}

The mean age was $22.1 \pm 0.97$ years. Only $2(3.1 \%)$ participants had Punjabi as the primary language while $63(96.9 \%)$ participants had Urdu as a primary language. $64(98.5 \%)$ participants were unmarried while only 1 participant was married. Five $(7.7 \%)$ participants were from rural areas and 60(92.3\%) participants were from urban areas. Nine (13.8\%) participants had previous neonatal resuscitation exposure and 56(86.2\%) had no such exposure (Table 1).

Paired sample t-test was used to compare the mean change in knowledge and skill score pre- and postintervention. Results indicated that the post-training sessions mean change in knowledge and skill scores was significant among participants (Table 2).

Results indicated that before the training session 60 participants have poor knowledge level while 5 participants had fair knowledge level. After the training session, out of 60 participants who had poor knowledge, 24 achieved good knowledge level and 32 achieved fair knowledge level whereas 4 participants did not improve their knowledge level. Out of 5 participants who had fair knowledge level, only 1 achieved a good knowledge level whereas 4 participants did not improve their knowledge level (Table 3)

Figure 1 showed that before the training session all participants have an unsatisfactory skill level. After the training session, out of 65 participants who had unsatisfactory skill level, 25 achieved good skill level and 34 achieved satisfactory levels whereas 6 participants did not improve their skill levels (Table 4).

Table 1: Demographic information of the participants

\begin{tabular}{|l|c|c|}
\hline Variable & No. & $\%$ \\
\hline Age (years) & \multicolumn{2}{|c|}{$22.1 \pm 0.97$} \\
\hline Year of professional education \\
\hline $3^{\text {rd }}$ & 32 & 49.2 \\
\hline $4^{\text {th }}$ & 33 & 50.8 \\
\hline Primary language & \multicolumn{2}{|}{} \\
\hline Urdu & 96.9 \\
\hline Punjabi & 3.1 \\
\hline Marital status & 2 & 98.5 \\
\hline Unmarried & 64 & 1.5 \\
\hline Married & 1 & 7.7 \\
\hline Residential area & 5 & 92.3 \\
\hline Rural & 60 & 13.8 \\
\hline Urban & \multicolumn{2}{|}{} \\
\hline Previous neonatal resuscitation exposure \\
\hline Yes & 9 & 86.2 \\
\hline No & 56 & \\
\hline
\end{tabular}

Table 2: Comparison of mean knowledge and skill score pre- and post-intervention

\begin{tabular}{|l|c|c|c|c|}
\hline \multicolumn{1}{|c|}{ Variable } & Pre & Post & Difference & p-value \\
\hline $\begin{array}{l}\text { Knowledge } \\
\text { score }\end{array}$ & $5.95 \pm 1.88$ & $11.58 \pm 2.10$ & $5.63 \pm 2.72$ & $<0.001$ \\
\hline Skill score & $3.28 \pm 1.11$ & $20.32 \pm 5.15$ & $17.05 \pm 4.98$ & $<0.001$ \\
\hline
\end{tabular}

Table 3: Comparison of knowledge level pre- and post-intervention

\begin{tabular}{|c|l|c|c|c|}
\hline \multicolumn{2}{|c|}{ Knowledge Level } & \multicolumn{3}{|c|}{ Post Training Session } \\
\cline { 2 - 5 } & Poor & $4(6.7 \%)$ & Fair & Good \\
\cline { 2 - 5 } Pre-Training Session & Fair & - & $32(53.3 \%)$ & $24(40.0 \%)$ \\
\cline { 2 - 5 } & Good & - & $4(80.0 \%)$ & $1(20.0 \%)$ \\
\hline
\end{tabular}

Table 4: Comparison of skill level pre- and post-intervention

\begin{tabular}{|c|l|c|c|c|}
\hline \multicolumn{2}{|c|}{ Skill Level } & \multicolumn{3}{|c|}{ Post Training Session } \\
\cline { 2 - 5 } & Unsatisfactory & Satisfactory & Good \\
\hline \multirow{3}{*}{ Pre-Training Session } & $6(9.2 \%)$ & $34(52.3 \%)$ & $25(38.5 \%)$ \\
\cline { 2 - 5 } & Satisfactory & - & - & - \\
\cline { 2 - 5 } & Good & - & - & - \\
\hline
\end{tabular}

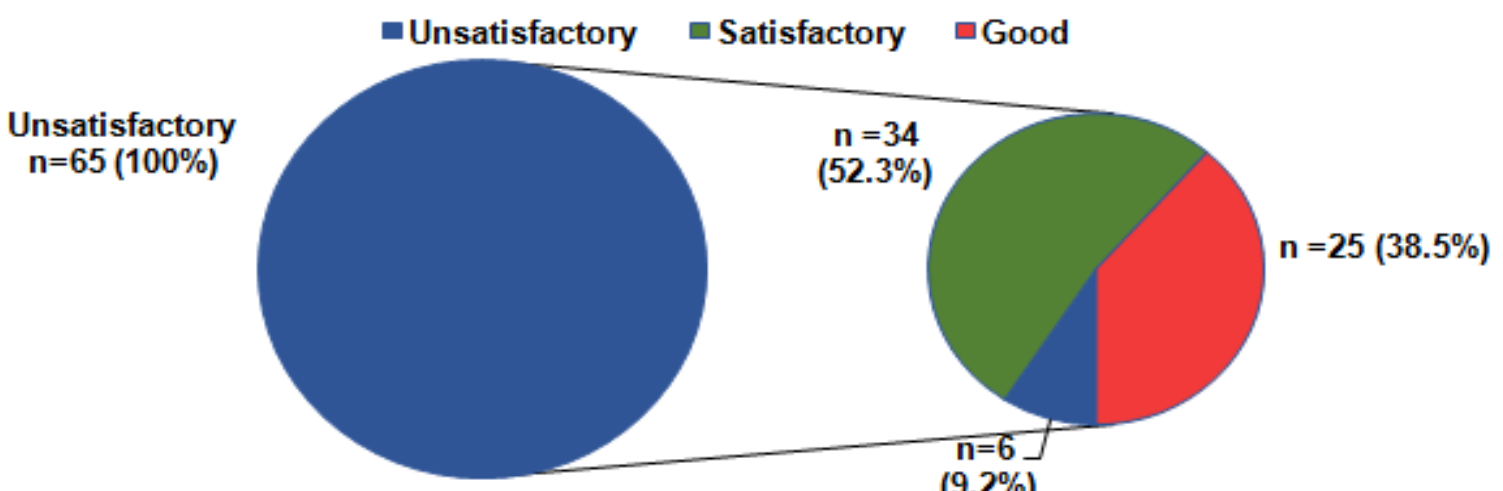

Pre Skill Status

$(9.2 \%)$

Post Skill Status

Fig.1: Comparison of mean skill pre- and post-intervention 


\section{DISCUSSION}

The current study aims to evaluate the effectiveness of diverse educational strategies in learning neonatal resuscitation among nursing students. The study results showed that nearly all nursing students had poor knowledge and skill before education in neonatal resuscitation. The results can be vindicated as nursing students had little exposure with no previous education in this essential skill. The results are also supported by Vural et $\mathrm{al}^{17}$ showed that $89 \%$ of nursing students had poor knowledge regarding ratio, while $84 \%$ had inadequate knowledge regarding the depth of chest compressions in India. In the context of Pakistan, the limited published literature is available regarding neonatal resuscitation. A cross-sectional study was conducted by Muneer et $\mathrm{al}^{18}$ at the Lahore General Hospital. The study reported that $50 \%$ of doctors were assisted by nurses during neonatal resuscitation. Although $90 \%$ of doctors knew resuscitation. Shockingly, no one had found to follow all the steps of resuscitation.

The study revealed that significant $(p<0.001)$ improvement in knowledge and skill was found after education based on diverse strategies in neonatal resuscitation. The results are in align with the study conducted by Mileder et al ${ }^{14}$ reported a significant increase in knowledge from the median in pre-test results was $62.1 \%$ while in post-test was $91.7 \%$ with $p=0.001$ in Austria. Similarly, the skill was improved significantly with $\mathrm{p}<0.001$ was found. The results were in accordance with the study conducted in Turkey by Kose et al. ${ }^{19}$ The study reported similar to our study results that the preintervention knowledge and skill of nursing students were poor while, after resuscitation training students significantly $(p=0.000)$ improve knowledge and practices in basic life support skills.

The results of the present supported by Helping Baby Breath (HBB) specially designed for developing areas. The HBB is integrated with diverse learning strategies and low dose high-frequency practices have been proven effective in many studies on enhancing knowledge and skills among health care providers. ${ }^{20-22}$ A study based on HBB education was conducted by Singhal et $\mathrm{al}^{23}$ among health professionals of Kenya and Pakistan. The study utilized innovative learning strategies and reported a gain in knowledge and skill in the posttest. Further, the addition of video in learning strategies is validated by Odongkara et $\mathrm{a}^{24}$ study conducted in Uganda. The authors reported that the addition of video debriefing in HBB education could increase its effectiveness and long-term retention.

To our knowledge, this is the first study to determine the effectiveness of diverse strategies in the education of neonatal resuscitation and evaluating the outcomes concerning knowledge, and skill among nursing students conducted in a Public School of Nursing in Lahore, Pakistan. The study provides valuable information for faculty and program directors who are charged with preservice curriculum reform in schools of midwifery and nursing. The study is also valuable to those who are responsible for in-service education of the same groups. However, the limitations include single centre study and the control group was not added that may limit its actual efficacy.

\section{CONCLUSION}

This study supports the efficacy of diverse educational methods in improving knowledge and skill in neonatal resuscitation. The significant gain in knowledge and skill occurs after educational intervention integrating with diverse strategies.

\section{RECOMMENDATIONS}

Neonatal resuscitation is an important emergency skill for nursing students. There is a need to develop strategies for effective training in the pre-service areas for health professionals. Future, multi-cantered randomized controlled trials with a large sample size are recommended for estimating the real efficacy of diverse educational methods in neonatal resuscitation.

Conflict of interest: Nil

\section{REFERENCES}

1. Williams J, Jones $\mathrm{D}$, Walker R. Consideration of using virtual reality for teaching neonatal resuscitation to midwifery students. Nurse Educ Prac 2018; 31: 126-9.

2. Garvey AA, Dempsey EM. Simulation in neonatal resuscitation. Frontiers Pediatr 2020; 8: 59.

3. Huang J, Tang Y, Tang J, et al. Educational efficacy of highfidelity simulation in neonatal resuscitation training: a systematic review and meta-analysis. BMC Med Educ 2019; 19(1): 1-10.

4. Sawyer T, Umoren RA, Gray MM. Neonatal resuscitation: advances in training and practice. Advances Med Educ Prac 2017; 8: 11

5. Mileder LP, GressI J, Urlesberger B, Raith W. Paramedics' newborn life support knowledge and skills before and after a targeted simulation-based educational intervention. Frontiers Pediatri 2019; 7: 132

6. Carolan-Olah M, Kruger G, Brown V, Lawton F, Mazzarino M. Development and evaluation of a simulation exercise to prepare midwifery students for neonatal resuscitation. Nurse Educ Today 2016; 36: 375-80.

7. Bull A, Sweet L. Midwifery students receiving the newborn at birth: A pilot study of the impact of structured training in neonata resuscitation. Nurse Educ Prac 2015; 15(5): 387-92.

8. Cheng A, Nadkarni VM, Mancini MB, et al. Resuscitation education science: educational strategies to improve outcomes from cardiac arrest: a scientific statement from the American Heart Association. Circulation 2018; 138(6): e82-e122.

9. Kim JY, Ahn HY. The effects of the 5-step method for infant cardiopulmonary resuscitation training on nursing students' knowledge, attitude, and performance ability. 2019; 25(1): 1727.

10. Kitson AL, Harvey G. Methods to succeed in effective knowledge translation in clinical practice. J Nursing Scholarship 2016; 48(3): 294-302.

11. Carolan-Olah M, Kruger G, Brown V, Lawton F, Mazzarino M, Vasilevski V. Communicating out loud: Midwifery students experiences of a simulation exercise for neonatal resuscitation. Nurse Educ Prac 2018; 29: 8-14.

12. Malarvizhi G, Glory H, Rajeswari S, Vasanthi BC. Outcome of clinical simulation on neonatal resuscitation in development of knowledge and skill among baccalaureate nursing students at a selected nursing institution. Asian J Nursing Educ Res 2017; 7(3): 417-22 
13. Kose S, Akin S, Mendi O, Goktas S. The effectiveness of basic life support training on nursing students' knowledge and basic life support practices: a non-randomized quasi-experimental design. Afr Health Sci 2020; 20(2): 966-76.

14. Mileder LP, Gressl J, Urlesberger B, Raith W. Paramedics' Newborn Life Support Knowledge and Skills Before and After a Targeted Simulation-Based Educational Intervention. Frontiers Pediatr 2019; 7: 132.

15. Abusaad F, Ebrahem G. The Changes on Knowledge, Confidence and Skills accuracy of Nursing students at a Simulated based setting versus Traditional during Neonatal Resuscitation. Int J Nursing Care 2015; 5(4): 11-22.

16. Rovamo L, Mattila M-M, Andersson S, Rosenberg $P$. Assessment of newborn resuscitation skills of physicians with a simulator manikin. Arch Dis Childhood Fetal and Neonatal 2011; 96(5): F383-F9.

17. Vural M, Koşar MF, Kerimoğlu O, et al. Cardiopulmonary resuscitation knowledge among nursing students: a questionnaire study. Anatolian J Cardiol 2017; 17(2): 140.

18. Muneer A, Bari A, Arslan Haider ASA. Knowledge of clinicians/pediatricians about neonatal resuscitation in a tertiary care hospital. Pak J Med Sci 2019; 35(3): 775.

19. Kose S, Akin S, Mendi O, Goktas S. The effectiveness of basic life support training on nursing students' knowledge and basic life support practices: a non-randomized quasi-experimental study. Afr Health Sci 2019; 19(2): 2252-62.

20. Hatamleh R, Abujilban S, Abuhammad S, Ariag DMA, Joseph RA. Effect of the Helping Babies Breathe Training Program: An Experimental Study on Jordanian Midwives' Knowledge and Skills. J Perinatal Neonatal Nursing 2021; 35(2): E11-E7.

21. Dol J, Campbell-Yeo M, Murphy GT, Aston M, McMillan D, Richardson B. The impact of the Helping Babies Survive program on neonatal outcomes and health provider skills: a systematic review. JBI Evidence Synthesis 2018; 16(3): 701-37.

22. Morris SM, Fratt EM, Rodriguez J, Ruman A, Wibecan L, Nelson BD. Implementation of the Helping Babies Breathe training program: a systematic review. Pediatrics 2020; 146(3).

23. Singhal N, Lockyer J, Fidler $\mathrm{H}$, et al. Helping Babies Breathe: global neonatal resuscitation program development and formative educational evaluation. Resuscitation 2012; 83(1): 906.

24. Odongkara B, Tylleskär T, Pejovic $\mathrm{N}$, et al. Adding videodebriefing to Helping-Babies-Breathe training enhanced retention of neonatal resuscitation knowledge and skills among health workers in Uganda: a cluster randomized trial. Global Health Action 2020; 13(1): 1743496 